\title{
ПОДХОДЫ К ДИФФЕРЕНЦИАЛЬНОЙ ДИАГНОСТИКЕ АНЕМИЧЕСКОГО СИНДРОМА У ПАЦИЕНТОВ С САХАРНЫМ ДИАБЕТОМ
}

\author{
Мусина Н.Н., Саприна Т.В., Прохоренко Т.С., Зима А.П.
}

ФГБОУ ВО Сибирский государственный медицинский университет Минздрава России, г.Томск, Россия

ЦЕЛЬ: изучить структуру анемического синдрома у пациентов с сахарным диабетом и установить новые маркеры, обладающие высокой информативностью в дифференциальной диагностике анемии при нарушении углеводного обмена.

МАТЕРИАЛЫ И МЕТОДЫ: исследование проводилось на базе эндокринологической клиники ФГБОУ ВО СибГМУ г. Томска. В исследование было включено 20 пациентов с сахарным диабетом 1 и 56 пациентов с сахарным диабетом 2 типа. Всем пациентам проводились: исследование гликированного гемоглобина и уровня креатинина с расчетом скорости клубочковой фильтрации по формуле CKD-EPI, оценивались количество эритроцитов, ретикулоцитов, концентрация гемоглобина, уровень гематокрита и биохимические показатели обмена железа - концентрация сывороточного железа и ферритина; проводилась оценка концентрации гепсидина и маркеров воспаления - СОЭ и высокочувствительного С-реактивного белка (СРБ). Полученные данные возраста, стажа заболевания, гликированного гемоглобина, индекса массы тела и микроальбуминурии не подчинялись нормальному закону распределения и были представлены в виде медианы и интерквартильного размаха (Me, $\left.\mathrm{Q}_{0,25}-\mathrm{Q}_{0,75}\right)$. Для показателей, имевших нормальное распределение (показатели обмена железа, СОЭ и СРБ), проводилась статистическая обработка с помощью критерия Стьюдента.

PЕЗУЛЬТАТЫ: в общей выборке пациентов частота железодефицитной (ЖДА) анемии составила 15,8\%, анемии хронических заболеваний (АХ3) - 38,1\%; в группе пациентов с сахарным диабетом 2 типа ЖДА была выявлена в 10,7\% случаев, АХ3 - в 41,1\% случаев; у пациентов с сахарным диабетом 1 типа частота как ЖДА, так и АХЗ составила 30,0\%. После разделения пациентов на группы по виду анемического синдрома - отсутствие анемии, АХЗ и ЖДА - был проведен сравнительный анализ средних значений маркеров воспаления и уровня гепсидина в данных группах. У пациентов с АХЗ уровень гепсидина был достоверно

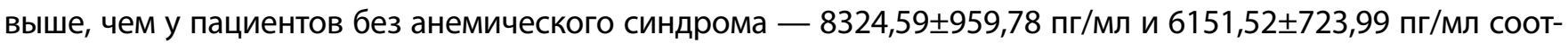

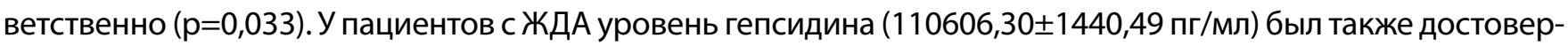
но выше, чем у пациентов без анемии ( $p=0,009)$, и выше, чем в случае AХ3. В группе АХЗ была достоверно

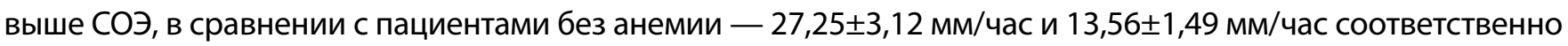
( $p<0,0001)$. По результатам ROC-анализа наибольшую информативность в диагностике AX3 в общей выборке пациентов показали: ферритин - чувствительность 78\%, специфичность 52\% при диагностическом пороге 75,5 нг/мл (площадь под кривой 0,695; p=0,006); СОЭ - чувствительность 67\%, специфичность 64\% при диагностическом пороге 15,5 мм/час (площадь под кривой 0,750; $\mathrm{p}=0,040$ ) и СРБ - чувствительность 67\%, специфичность 64\% при диагностическом пороге 5,2 нг/мл (площадь под кривой 0,646; р<0,0001), а в группе пациентов с сахарным диабетом 2 типа - гепсидин - чувствительность 71\%, специфичность 52\% при диагностическом пороге 6545,5 пг/мл (площадь под кривой 0,631; $\mathrm{p}=0,082$ ).

ВЫВОДЫ: таким образом, СОЭ, СРБ, и гепсидин в совокупности с классическим диагностическим параметром - ферритином, продемонстрировали высокую диагностическую ценность в отношении АХ3 и могут быть внесены в модифицированный алгоритм дифференциальной диагностики анемического синдрома.

ИСТОЧНИК ФИНАНСИРОВАНИЯ - грант РФФИ Аспиранты №19-315-90061 «Взаимосвязь нарушений феррокинетики и метаболических изменений при сахарном диабете». 